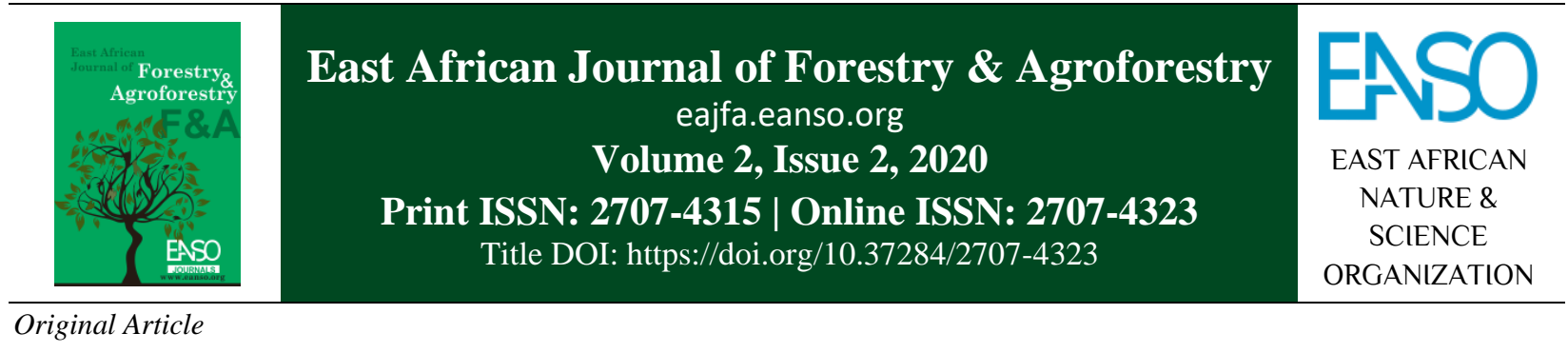

\title{
Spatial and Temporal Characteristics of Climate Change in Kakamega Tropical Rainforest Ecosystem of Kakamega County, Kenya
}

\author{
John Ayieko Aseta ${ }^{*}$, Prof. Paul A. Omondi ${ }^{1} \&$ Dr. Abdirizak A. Nunow ${ }^{1}$ \\ ${ }^{1}$ Department of Geography, Moi University, Kenya. \\ *Author for Correspondence email: jaseta@kafuco.ac.ke or asetajohn@gmail.com.
}

Article DOI: https://doi.org/10.37284/eajfa.2.2.43

\section{Date Published: ABSTRACT}

09 November 2020 The main objective of this study was to establish the spatial and temporal characteristics of climate change in the Kakamega Tropical Rainforest. This

Keywords: study was descriptive and cross-sectional in design and relied on a mixed

Climate Change, Spatial and Temporal

Characteristics, Kakamega Tropical

Rainforest,

Kakamega County. methods methodology. Anthropogenic Global Warming Theory and Adaptive Management Theory were used to guide the study. A conceptual framework showing the interrelationship between the dependent and independent variables was outlined. The study utilized both secondary and primary data. The target population was 200 households living up to $10 \mathrm{~km}$ from the forest edge in the selected communities neighbouring Kakamega Tropical Rainforest and 20 government officials within Kakamega County. A total of 119 members of the households and 20 forest officers were sampled as respondents in the study. The study findings revealed that the spatial and temporal characteristics of climate change were very extreme temperatures and precipitation (the results revealed that temperature is increasing by $0.04{ }^{\circ} \mathrm{C}$ per annum while rainfall amounts have dropped by $150 \mathrm{~mm}$ for the past fifty-three years in the region). The study recommended that there is a need to conserve the forest to get rid of extreme temperatures and precipitation since it was a source of many services to the surrounding communities and that the forest ecosystem also helped to adapt or mitigate climate change among others.

\section{APA CITATION}

Aseta, J., Omondi, P., \& Nunow, A. (2020). Spatial and Temporal Characteristics of Climate Change in Kakamega Tropical Rainforest Ecosystem of Kakamega County, Kenya. East African Journal of Forestry and Agroforestry, 2(2), $45-53$. https://doi.org/10.37284/eajfa.2.2.43 


\section{CHICAGO CITATION}

Aseta, John, Paul Omondi, and Abdirizak Nunow. 2020. "Spatial and Temporal Characteristics of Climate Change in Kakamega Tropical Rainforest Ecosystem of Kakamega County, Kenya”. East African Journal of Forestry and Agroforestry 2 (2), $45-53$. https://doi.org/10.37284/eajfa.2.2.43.

\section{HARVARD CITATION}

Aseta, J., Omondi, P. and Nunow, A. (2020) "Spatial and Temporal Characteristics of Climate Change in Kakamega Tropical Rainforest Ecosystem of Kakamega County, Kenya”, East African Journal of Forestry and Agroforestry, 2(2), pp. 45-53. doi: 10.37284/eajfa.2.2.43.

\section{IEEE CITATION}

J. Aseta, P. Omondi, and A. Nunow, "Spatial and Temporal Characteristics of Climate Change in Kakamega Tropical Rainforest Ecosystem of Kakamega County, Kenya”, EAJFA, vol. 2, no. 2, pp. 45-53, Oct. 2020.

\section{MLA CITATION}

Aseta, John, Paul Omondi, and Abdirizak Nunow. "Spatial and Temporal Characteristics of Climate Change in Kakamega Tropical Rainforest Ecosystem of Kakamega County, Kenya". East African Journal of Forestry and Agroforestry, Vol. 2, no. 2, Nov. 2020, pp. 45-53, doi:10.37284/eajfa.2.2.43.

\section{INTRODUCTION}

Changes in temperature have been extensively studied and are well understood across a wide range of temporal and spatial scales. The Fifth Assessment Report from the Intergovernmental Panel on Climate Change Working Group illustrated that the globally averaged land surface air temperature has risen since the $19^{\text {th }}$ century by an average increase of 0.72 degrees Celsius from 1951 to 2012, the greatest amount of warming occurring since the 1970s (Stocker et al., 2013). However, trends in precipitation, globally and regionally, are less obvious. Precipitation in the tropics (30 degrees $\mathrm{N}$ to 30 degrees $\mathrm{S}$ latitude) has both decreased and increased since the 1970s; precipitation has increased in the last decade (2000s), reversing the drying trend observed from the 1970s to late 1990s (Stocker et al., 2013).

At smaller spatial scales minimum temperature on the island of Oahu in Hawaii, USA has an average increase of 0.17 degrees Celsius per decade (Safeeq et al., 2013) and the state-wide average warming for Hawaii is 0.2 degrees Celsius per decade since 1975 (Giambelluca et al., 2008). The complexity of precipitation trends is even greater when comparing changes at smaller spatial scales, as significant differences in annual precipitation trends have been observed across three islands in the Hawaiian Archipelago (Chen \& Chu, 2014). The island of Hawaii itself has seen a predominately positive annual precipitation trend, as well as precipitation intensity, though most of the increase is located in the high elevations surrounding Mt. Mauna Loa. Opposite trends, with decreasing precipitation intensity are seen on the much drier, western side of the island (Chu et al., 2010). These localized and regional spatial patterns of precipitation dictate water resources on the island scale, with regions of highest precipitation home the highest resource availability (Hawaii County Plan, 2010).

Therefore, patterns then play a large role in resource management, especially in tropical island settings where freshwater resources quickly meet the ocean (Falkland, 1999). Changes in precipitation patterns lead to concerns for water resource management as extreme events, such as droughts and floods, will likely occur more frequently and with a higher severity in the future (Brekke et al., 2009). In Hawaii in particular, declines in base flow and low-stream flow have been noted across the entire Hawaiian Archipelago (Bassiouni \& Oki, 2013); though only surface water records were used, the decline in flow indicate a long-term decrease in water resources availability state-wide, including Kona where only minimal surface water is available (Hawaii County Plan, 2010).

The interaction between climatic elements, vegetation attributes and ocean surface temperature variations are not properly explained and there are contrasts from area to another throughout the world. As per numerous past studies, the climate parameters and the Normalized Difference vegetation index (NDVI) have a positive connection in some area (Nicholson et al., 1990); 
while it is negative in other areas depending on geographical position, geomorphology, vegetation type, climatic condition and other factors (Zhong et al., 2010).

Vegetation condition is dependent on soil type, the moisture of soil and type of vegetation in the area; in addition, climatic elements, for example, temperature, precipitation and ocean surface temperature. Among those numerous elements of vegetation dynamics, the climatic elements are very unpredictable and variable in a very short period of time, spatially and temporally (Zhong et al., 2010). Precipitation varies more in both space and time than other climatic elements. All other factors of vegetation dynamics are most likely dependent on climatic elements and they do not vary temporally in a very short period of time like temperature and precipitation. This spatiotemporal variation of climatic factors has a great influence on the vegetation dynamics and seasonal farming productivities (Nicholson et al., 1990).

Because of overexploitation through enormous lawful and unlawful logging between the years the 1960 s and 1990s, Kakamega forest flora is dominated by a mixture of large secondary-growth trees and hardly any primary-growth trees. Even for this secondary forest, much of the closed canopy and contiguity exists only in the northern part of the forest, consisting of the Buyangu blocks, which are now protected as a national wildlife reserve. The southern end, involving the Ikuywa, Yala and Isecheno just as the isolate units of the Malava, Kisere, and Kaimosi blocks, are managed as forest reserves but are still accessible to the local public community despite some level of official restriction (Bennun et al., 1999).

In Ethiopia, Gojam area, most of the population depends on rainfall-based agriculture and agricultural related activities for their livelihoods. These days, the occasional rainfall is not coming on time and is reducing in amount (UNFCCC, 2010). Precipitation variance has noteworthy long- and short-term impacts on natural resources, especially wetlands, rivers, forests and lakes. The economy of the Gojam populace is mainly based on rain-fed agriculture. Regardless of the availability of surface and groundwater resources, the failure of seasonal rains seriously affects the area's agricultural activities that lead to food insecurity and other hardships.

The World Meteorological Organization (WMO, 2011) states that climate variability represents variations in the mean state and other statistics, (for example, standard deviations, the occurrence of extremes, and so on.) of the climate on all temporal and spatial scales beyond that of individual weather events. The term is regularly used to indicate deviations of climatic statistics over a given timeframe (for instance a season, year or month) from the long-term statistics relating to the corresponding calendar period. Variations might be because of natural internal processes within the climate system (internal variability), or to variations in natural or anthropogenic external forcing (external variability).

In the smaller spatial scales, the vegetation index is partly associated with root depth, vegetation types and soil properties. In addition, little is known quantitatively, with respect to the degree to which spatial variation of the vegetation index relies upon rainfall seasonality in tropical rainforest at a regional scale (Barbosa \& Kumar, 2011). Geostatistically based spatial and temporal analyses of NDVI and other related climatic parameters would be useful to understand how they would be related to each other in the zone and to make predictions of a parameter based on the signal of another one.

The factors or driving forces can be classified as human and natural induced. In the study area, the natural driving forces/factors might be generally geological or meteorological phenomena like an earthquake, soil type, steep relief, tremor, and extreme precipitation. Population pressure, immense agricultural and deforestation, as well as plough of grass or bushland caused by the population increase, are also human factors. In the last few decades, the conversion of grasslands, forest and woodland into cropland and pasture has risen significantly in the tropics (Shiferaw \& Singh, 2011). A significant increase in cultivated land instead of forestland was found to have occurred between 1957 and 1995 in Gojam (Shiferaw \& Singh, 2011). The most significant changes were the destruction of the natural vegetation, expansion of grazing land and increased farms. 
Climate is explained in terms of the variability of relevant atmospheric variables, for example, wind, humidity, snowfall, temperature, clouds, precipitation including extreme or occasional ones, over a long time in a specific area. The classical period for performing the statistics used to define climate corresponds to at least 3 decades, and it is designated by the "climate normal period", as defined by the World Meteorological Organization (WMO). As a consequence, the 30-year period proposed by the WMO should be considered more as an indicator than a norm that must be followed in all cases. This meaning of the climate as representative of conditions over several decades should, of course, not mask the fact that climate can change rapidly. Climate can thus be viewed as a synthesis or aggregate of weather in a particular area and for a long time (Goosse et al., 2010). This involves the region's general pattern of weather conditions, seasons and weather extremes like droughts, rainy or hurricanes periods. Two of the most significant variables determining an area's climate are precipitation and air temperature (Goosse et al., 2010).

There is need to also consider the fact that the state of the atmosphere used in defining the climate given above is influenced by numerous processes involving not only the atmosphere but also the vegetation, the sea ice, the ocean, etc. Climate is thus now more and more frequently defined in a wider sense as the statistical description of the climate system (Goosse et al., 2010). This includes the analyses of the behaviour of its five major components: cryosphere; solid water, i.e. sea ice, glaciers, ice sheets, etc., biosphere (all the living organisms), the atmosphere; the gaseous envelope surrounding the Earth, the land surface and the hydrosphere; liquid water, i.e. ocean, lakes, underground water, etc., and the interactions between them (Solomon et al., 2007).

It has also been projected that global mean surface temperatures will increase a further $0.3{ }^{\circ} \mathrm{C}$ to 1.7 ${ }^{\circ} \mathrm{C}, 1.1{ }^{\circ} \mathrm{C}$ to $2.6^{\circ} \mathrm{C}, 1.4{ }^{\circ} \mathrm{C}$ to $3.1^{\circ} \mathrm{C}$, and $2.6^{\circ} \mathrm{C}$ to $4.8{ }^{\circ} \mathrm{C}$ by the end of this century (2081-2100), relative to 1986-2005 under RCP (Representative Concentration Pathway) 2.6, RCP4.5, RCP6.0 and RCP8.5 respectively with considerable anomalies in the rainfall (Figures 2.1 and 2.2) (IPCC, 2014). Therefore, it can be hypothesized that climate change will substantially affect the ecosystem services supply in this century.

Figure 1: Projected global average surface temperature change over 2006 to 2100 relative to 19862005

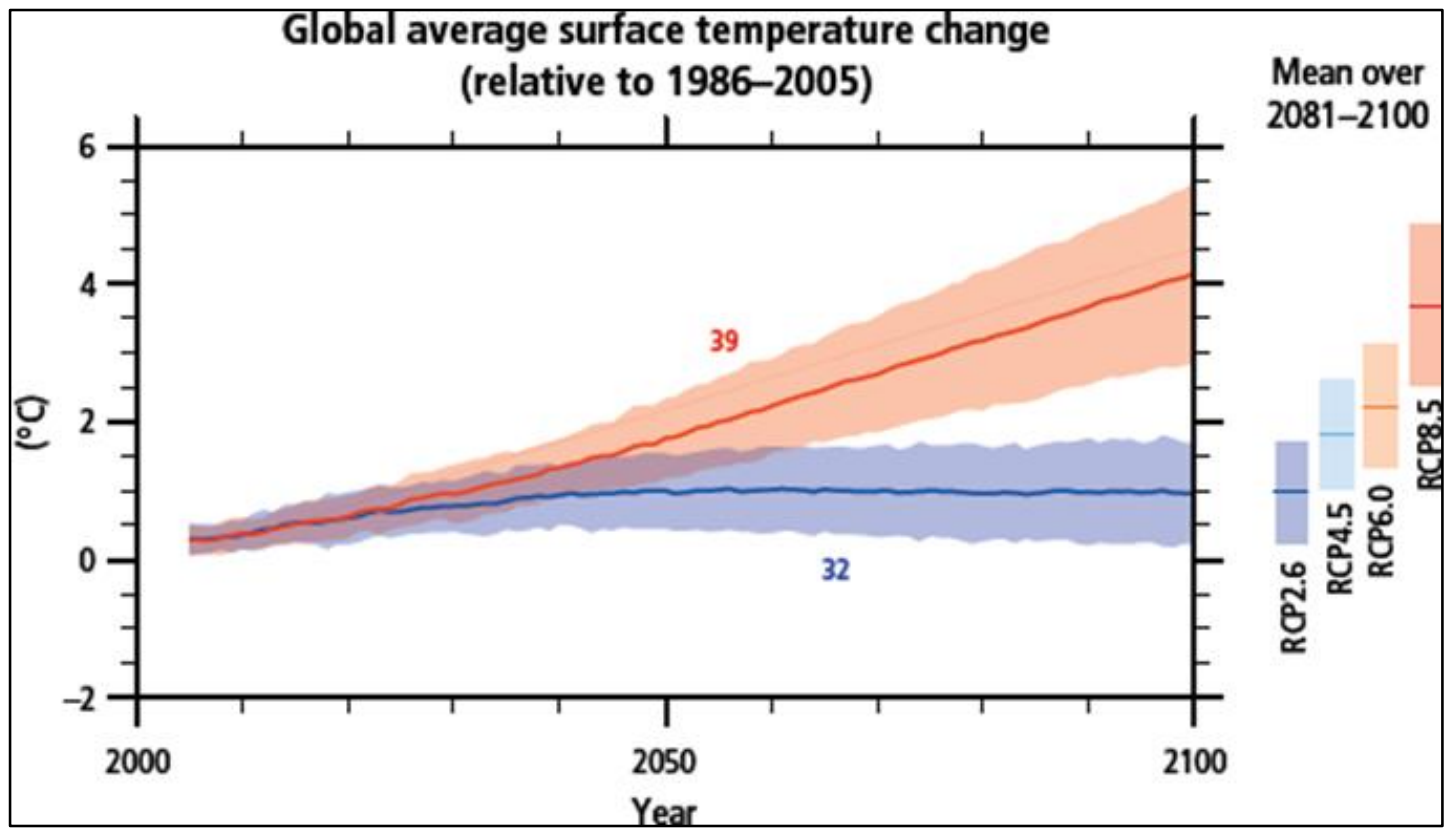

Source: (IPCC, 2014, p. 11) 
Figure 2: Projected global average surface temperature (a) and rainfall change (b)

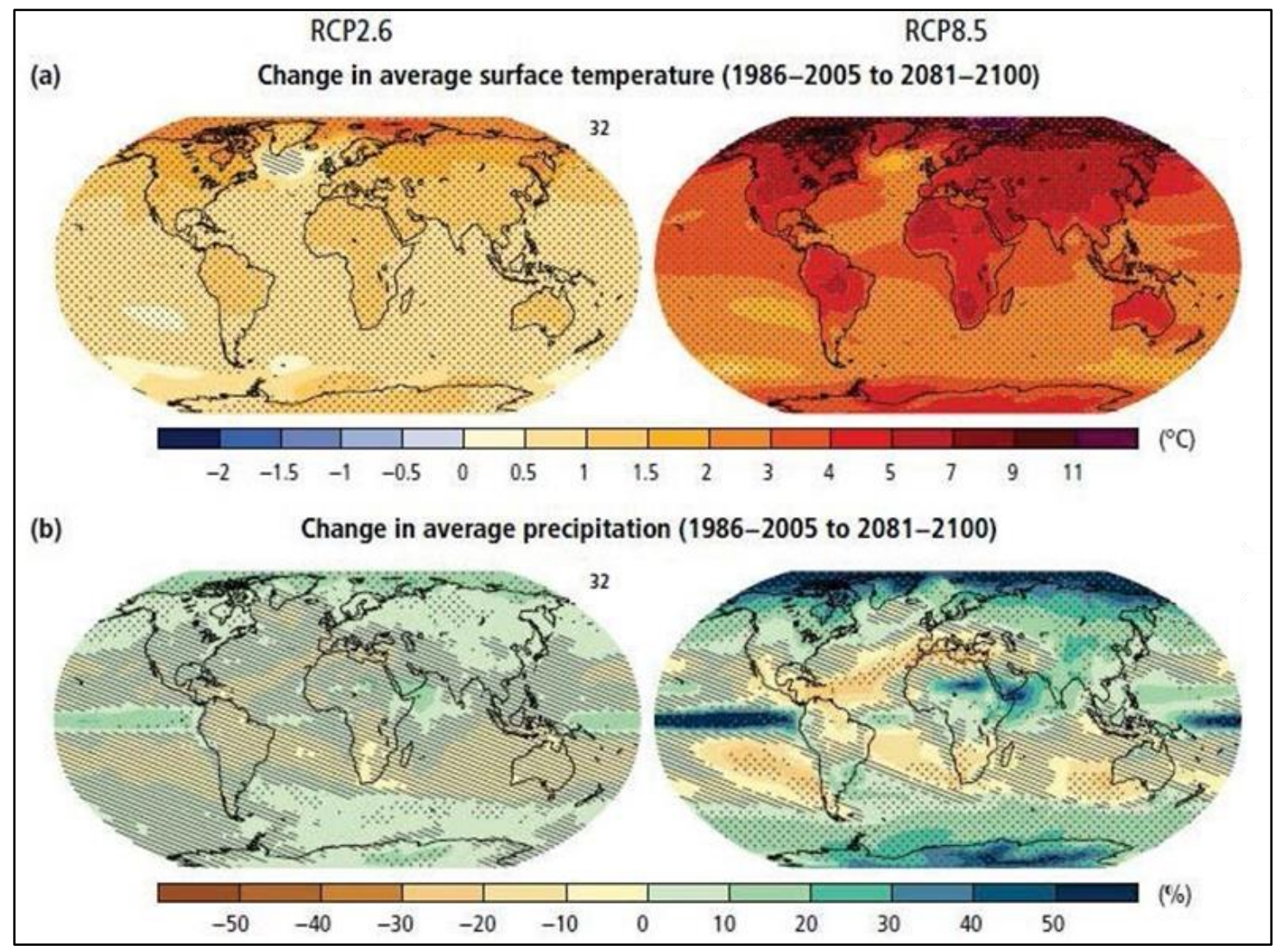

Source: (IPCC, 2014)

Tropical forests are thus significant for climate change mitigation, but climate change in turn also influences the temporal dynamics of tropical forests and consequently their mitigation capacity. Spatial variation in abiotic conditions, for example, soil fertility and yearly precipitation highly determine spatial variation in biomass (Malhi, 2012; Poorter et al., 2015), and therefore temporal changes in abiotic conditions can lead to temporal changes in biomass stocks and other ecosystem processes. Moreover, biotic conditions, which are properties of the vegetation itself, for example, species diversity and community weighted mean characteristics, can determine ecosystem processes and in this way the climate mitigation potential of tropical forests.

\section{RESEARCH METHODOLOGY}

This study was descriptive and cross-sectional in design and it relied on a mixed methods methodology. According to Joppe (2000), a descriptive survey study helps to gather data at a particular point in time with the intention of describing the nature of existing conditions, identifying standards against which existing conditions can be compared and determining the relations that exist between specific events.

Mugenda (2010) recommends the design to collect data in order to answer questions concerning the current status of the subject in the study. Surveys can be used for explaining or exploring the existing status of two or more variables at a given point in time. The design enables the researcher to have a wider coverage and comprehensive description of the observed characteristics and interrelationship in the target population (Creswell \& Miller, 2005). 
Descriptive survey design enables the researcher to collect original data for the purposes of describing and measuring the characteristics of a population, which is too large to be observed directly. The design was selected because it was very convenient in collecting substantial amount of views from respondents over a wide area using limited resources (Kombo \& Tromp, 2006). Therefore, the variables that were studied were at their natural occurrence and not manipulated by the researcher. The survey method was appropriate because it is a self-report study, which requires the collection of quantifiable information from the sample. This involved collection of both quantitative and qualitative data. The study was concerned with the establishment of the spatial and temporal characteristics of climate change in Kakamega Tropical Rainforest.

\section{DISCUSSION OF RESEARCH FINDINGS}

The objective of this study was to establish the spatial and temporal characteristics of climate change in the Kakamega Tropical Rainforest. In a bid to answer this question, several questions were put forward. They included finding out their understanding of climate change. The results are summarized in Table 1 below.

Table 1: Spatial and Temporal Characteristics of Climate Change in Kakamega Tropical Rainforest

\begin{tabular}{|c|c|c|c|c|c|c|c|c|}
\hline \multirow[t]{2}{*}{ Item } & \multirow[t]{2}{*}{ Category } & \multicolumn{2}{|c|}{ Agreed } & \multicolumn{2}{|c|}{ Undecided } & \multicolumn{2}{|c|}{ Disagreed } & \multirow{2}{*}{$\begin{array}{l}\text { Total } \\
\text { F }\end{array}$} \\
\hline & & $\mathbf{F}$ & $\%$ & $\mathbf{F}$ & $\%$ & $\mathbf{F}$ & $\%$ & \\
\hline \multirow[t]{2}{*}{ Climate change is very extreme temperatures } & HM & 96 & 80.7 & 4 & 3.4 & 19 & 15.9 & 119 \\
\hline & FO & 20 & 100 & - & - & - & - & 20 \\
\hline \multirow[t]{2}{*}{ Climate change is very extreme precipitation } & HM & 88 & 73.9 & 13 & 10.9 & 18 & 15.2 & 119 \\
\hline & FO & 20 & 100 & - & - & - & - & 20 \\
\hline \multirow{2}{*}{$\begin{array}{l}\text { Climate change is both extreme temperatures } \\
\text { and precipitation }\end{array}$} & $\mathrm{HM}$ & 97 & 81.5 & 10 & 8.4 & 12 & 10.1 & 119 \\
\hline & $\mathrm{FO}$ & 14 & 70 & 6 & 30 & - & - & 20 \\
\hline \multirow{2}{*}{$\begin{array}{l}\text { Shift in the rainy and dry season is a visible } \\
\text { change in climate }\end{array}$} & HM & 99 & 83.2 & 5 & 4.2 & 15 & 12.6 & 119 \\
\hline & FO & 20 & 100 & - & - & - & - & 20 \\
\hline \multirow{2}{*}{ Drought is a visible change in climate } & HM & 77 & 64.7 & 10 & 8.4 & 32 & 26.9 & 119 \\
\hline & FO & 19 & 95 & 1 & 5.0 & - & - & 20 \\
\hline \multirow[t]{2}{*}{ Intense rainfall is a visible change in climate } & $\mathrm{HM}$ & 88 & 73.9 & 15 & 12.6 & 16 & 13.5 & 119 \\
\hline & $\mathrm{FO}$ & 14 & 70 & 6 & 30 & - & - & 20 \\
\hline \multirow[t]{2}{*}{ Less rainfall is a visible change in climate } & HM & 92 & 77.3 & 18 & 15.1 & 9 & 7.5 & 119 \\
\hline & $\mathrm{FO}$ & 18 & 90 & 2 & 10 & - & - & 20 \\
\hline
\end{tabular}

The members of the households were asked what they perceived to be climate change. Among those who viewed climate change as very extreme temperatures, the majority of them at 96 et $80.7 \%$ ) agreed, 19 (16\%) disagreed, while only 4 (3.4\%) were undecided (see Table 1). Among those who viewed climate change as very extreme precipitation, a majority of them at 88 (74\%) agreed, $18(15.2 \%)$ disagreed while a few 13 $(10.9 \%)$ were undecided (see Table 1). Among those who viewed climate change as both very extreme temperatures and precipitation, a majority of them again at $97(81.5 \%)$ agreed, $12(10.1 \%)$ disagreed while $10(8.4 \%)$ were undecided (see Table 1). This shows that a majority of the members of the households' respondents viewed climate change as extreme changes in both temperatures and precipitation.

The views on the same question posed to forest officers were not different. All $20(100 \%)$ of the forest officers agreed that climate change had very extreme temperatures (see Table 1). On the other hand, all $20(100 \%)$ of the forest officers agreed that climate change had very extreme precipitation. On whether climate change was having both extreme temperature and precipitation a majority at 14 $(70 \%)$ of the forest officers indeed agreed, while 6 (30\%) were undecided on the issue (see Table 1).

This shows that both the members of the households and the forest officers were of the view that climate change had extreme temperature and 
precipitation, views supported by Safeeqet et al. (2013) who argues that at smaller spatial scales minimum temperature on the island of Oahu in Hawaii, USA has an average increase of 0.17 degrees Celsius per decade and the statewide average warming for Hawaii is 0.2 degrees Celsius per decade since 1975 (Giambelluca et al., 2008). The complexity of precipitation trends is even greater when comparing changes at smaller spatial scales, as significant differences in annual precipitation trends have been observed across three islands in the Hawaiian Archipelago (Chen and Chu, 2014).

When asked if the members of the households have ever witnessed climate change, a majority at 83 $(69.7 \%)$ agreed while a few at 36 (30.3\%) disagreed. When the same question was posed to the forest officers, similar results were obtained with a majority of $12(60 \%)$ indicating agreed while $8(40 \%)$ disagreed. This shows that climate change is a normal observable occurrence that can be witnessed by people living near the forest. This is in agreement with the Stocker et al. (2013) views that changes in temperature have been extensively studied and are well understood across a wide range of temporal and spatial scales.

When the members of the households were asked to indicate the spatial and temporal characteristic of climate change in Kakamega Tropical Rainforest, those who viewed that as a shift in the rainy and dry season, a majority at $99(83.2 \%)$ agreed while only a few at $15(12.6 \%)$ disagreed and only $5(4.2 \%)$ were undecided. On the other hand, among the forest officers, all the $20(100 \%)$ agreed that it was indeed a shift in the rainy and dry season.

The members of the households who felt that the spatial and temporal characteristics of climate change were the drought, a majority at $77(64.7 \%)$ agreed, 32 (26.9\%) disagreed while only 10 (8.4\%) were undecided. On the other hand, among the forest officers', the majority at 19 (95\%) agreed while only $1(5 \%)$ was undecided. This shows that the majority of the household's respondents and forest officers' respondents view drought as one of the consequences of climate change. These views are supported by Goosse et al. (2010) who argue that climate change includes the region's general pattern of weather conditions, seasons and weather extremes like hurricanes, droughts, or rainy periods.

The other variable that the members of the households were supposed to respond to was if they felt that the spatial and temporal characteristics of climate change were intense rainfall. A majority at $88(73.9 \%)$ agreed, $16(13.5 \%)$ disagreed, while 15 $(12.6 \%)$ were undecided. On the other hand, a majority of the forest officers at $14(70 \%)$ agreed that it was intense rainfall while the rest $6(30 \%)$ were undecided. This shows that majority of the members of the household and forest officers agreed that intense rainfall was part of the effect of climate change as supported by Goosse et al. (2010).

When asked whether the spatial and temporal characteristics of climate change was less rainfall, a majority at $92(77.3 \%)$ of the members of the household agreed, $9(7.5 \%)$ disagreed while 18 $(15.1 \%)$ were undecided. On the other hand, a majority at $18(90 \%)$ of the forest officers agreed, while only $2(10 \%)$ were undecided. This agrees with the views of Goosse et al. (2010) about less rainfall being a consequence of climate change.

\section{SUMMARY OF THE FINDINGS}

The members of the households were asked what they perceived to be climate change. The majority viewed climate change as very extreme temperatures, very extreme precipitation and also both as very extreme temperatures and precipitation, and this shows that a majority of the members of the households' respondents viewed climate change as both extreme changes in both temperatures and precipitation. These views are in line with those of Goosse et al. (2010).

The views on the same question posed to forest officers were not different; all the forest officers agreed that climate change was having both very extreme temperatures and precipitation. This shows that both the members of the households and the forest officers were of the view that climate change was the cause of extreme temperatures and precipitation, views supported by Safeeqet et al. (2013).

A majority of both the members of the households and forest officers had witnessed climate change in 
the area. This shows that climate change is a normal observable occurrence that can be witnessed by people living near the forest. This is in agreement with the views of Stocker et al. (2013).

When the members of the households and forest officers were both asked to indicate the spatial and temporal characteristics of climate change in the Kakamega Tropical Rainforest, the majority viewed that as a shift in the rainy and dry seasons.

A majority of both the members of the households and forest officers felt that one of the spatial and temporal characteristics of climate change was drought. This shows that the majority of the households' respondents and forest officers' respondents view drought as one of the consequences of climate change. These views are supported by those of Goosse et al. (2010). A majority of the members of the households and forest officers also felt that one of the spatial and temporal characteristics of climate change was intense rainfall. This shows that majority of the members of the households and forest officers agreed that intense rainfall was part of the effect of climate change.

A majority of both the members of the households and forest officers agreed that one of the spatial and temporal characteristics of climate change was less rainfall. This agrees with the views of Safeeqet et al. (2013) about less rainfall being a consequence of climate change.

\section{CONCLUSIONS AND RECOMMENDATIONS}

This study concluded that Spatial and Temporal Characteristics of Climate Change in the Kakamega Tropical Rainforest were very extreme temperatures and precipitation. The majority of the respondents had witnessed climate change in the area.

There is a need to conserve the Kakamega Tropical Rainforest so that we can get rid of very extreme temperatures and very extreme precipitation since many respondents had witnessed climate change in the area due to the destruction of the ecosystem.

\section{REFERENCES}

Bassiouni, M., \& Oki, D. S. (2013). Trends and shifts in streamflow in Hawaii, 1913-2008. Hydrological Processes, 27(10), 1484-1500. doi: 10.1002/hyp.9298

Bennun, A.L., Njoroge P. (1999). Important Birds Areas in Kenya. Nairobi, Kenya: East Africa Natural History Society.

Brekke, L. D., Kiang, J. E., Olsen, J. R., Pulwarty, R. S., Raff, D. A., Turnipseed, D. P., Webb, R. S., White, K. D. (2009). Climate Change and Water Resources Management: A Federal Perspective. Circular 1331 U.S. Department of the Interior, U.S. Geological Survey.

Chen, Y. R. \& Chu, P. S. (2014). Trends in precipitation extremes and return levels in the Hawaiian Islands under a changing climate. International Journal of Climatology, 34(15), 3913-3925.

Chu, P. S., Chen, Y. R. \& Schroeder, T. (2010). Changes in Precipitation Extremes in the Hawaiian Islands in a Warming Climate. Journal of Climate, 23(18), 4881-4900. doi: 10.1175/2010JCLI3484.1

Falkland, A. (1999). Tropical island hydrology and water resources: Current knowledge and future needs. Paper presented. 2nd International Colloquium on Hydrology and Water Management in the Humid Tropics. Panama: Rep. of Panama. UNESCO-IHP. 22-26 March 1999.Giambelluca, T. W., Diaz, H. F., \& Luke, M. S. (2008). Secular temperature changes in Hawaii. Geophysical Research Letters, 35(12). doi: 10.1029/2008GL034377

Goosse, H., Barriat, P. Y., Loutre, M. F., \& Zunz, V. (2010). Introduction to climate dynamics and climate modelling. Centre de recherche sur la Terre et le climat Georges LemaîtreUCLouvain.

Hawaii County Plan, (2010). Water Use and Development Plan

Intergovernmental Panel on Climate Change (IPCC). (2014). Climate Change 2014 - 
Impacts, Adaptation and Vulnerability: Part A: Global and Sectoral Aspects: Working Group II Contribution to the IPCC Fifth Assessment Report. Cambridge: Cambridge University Press. doi: 10.1017/CBO9781107415379

Malhi, Y. (2012). The productivity, metabolism and carbon cycle of tropical forest vegetation. Journal of Ecology, 100(1), 65-75.

Nicholson, S. E., Davenport, M. L., \& Malo, A. R. (1990). A comparison of the vegetation response to rainfall in the Sahel and East Africa, using normalized difference vegetation index from NOAA AVHRR. Climatic change, 17(2-3), 209-241.

Poorter, L., van der Sande, M. T., Thompson, J., Arets, E. J., Alarcón, A., Álvarez-Sánchez, J., ... \& Bongers, F. (2015). Diversity enhances carbon storage in tropical forests. Global Ecology and Biogeography, 24(11), 13141328.

Safeeq, M., Mair, A., \& Fares, A. (2013) Temporal and spatial trends in air temperature on the Island of Oahu, Hawaii. International Journal of Climatology, 33(13), 2816-2835. doi: 10.1002/joc.3629

Shiferaw, A., \& Singh, K. L. (2011). Evaluating the land use and land cover dynamics in Borena Woreda South Wollo Highlands, Ethiopia. Ethiopian Journal of Business and Economics, 2(1), 69-104.

Solomon, S., D., Qin, M., Manning, Z., Chen, M., Marquis, K. B., Averyt, M., Tignor \& Miller, H. L. (Eds.). (2007). Climate Change: The Physical Science Basis. Contribution of Working Group I to the Fourth Assessment Report of the Intergovernmental Panel on Climate Change. Cambridge, UK \& New York, NY: Cambridge University Press.

Stocker, T. F., Qin, D., Plattner, G., Tignor, M. M. B., Allen, S. K., Boschung, J., Nauels, A., Xis, Y., Bex, V. \& Midgley, P. M. (Eds). (2013). Climate Change 2013: The Physical Science Basis. Working Group I Contribution to the Fifth Assessment Report of the Intergovernmental Panel on Climate Change.
New York, NY: Cambridge University Press \& Intergovernmental Panel on Climate Change.

UNFCCC. (2010). Climate Change: Impacts, Vulnerabilities and Adaptation in Developing Countries. United Nations Framework Convention on Climate Change (UNFCCC), Climate Change Secretariat.

WMO. (2011). Frequently Asked Questions (FAQs). World Meteorological Organization, Commission for Climatology. Available at: http://www.wmo.int/pages/prog/wcp/ccl/faqs. php

Zhong, L., Ma, Y., Salama, M. S., \& Su, Z. (2010). Assessment of vegetation dynamics and their response to variations in precipitation and temperature in the Tibetan Plateau. Climatic change, 103(3-4), 519-535. 